\title{
Results of Personal Requirements Research of People with Different Social Status
}

\section{Suhova E.V.}

\author{
Samara State University of Economics, Russia, 443090, Samara, Sovetskoi Armii Street, 141; Correspondence: Samara State \\ University of Economics, 443090, Russia, Samara, Sovetskoi Armii Street, 141, Email: lenusasulhova@yandex.ru
}

\author{
Doi:10.5901/mjss.2015.v6n6s3p360
}

\begin{abstract}
Absract
With the help of the questionnaire on studying personal needs of people with different social status developed by the author three groups of people were questioned. In the basis of the questionnaire is the theory of Maslow A. One group consisted of practically healthy people; the second group - of people with chronic obstructive pulmonary disease, their social status was the same. And the third group consisted of people with chronic tuberculosis. They had similar changes in lungs as the people from the second group but their social status was low. The results showed that all the personal needs of the sick persons are reduced except the need in respect. Personal needs are dependent on the state of health except the need in respect. The need in respect is more important than health. The need in respect can be used as motivation for work, treatment, training and career development.
\end{abstract}

Keywords: personal needs, questioning, the need in respect, the need in respect as motivation.

\section{Introduction}

Sociologists, psychologists, philosophers, economists and doctors deal with the problem of personal needs and their satisfaction (Patosha O.I., 2008, Stepanova E.N. \&Eflova M.A., 2012, Suhova E.V. \& Lebedeva N.O., 2005). The views of scientists changed over time (Vahitova Z.Z., 2004, Ivanova N.L., 2012, Breakwell G.M. 2010). Personal needs were recognized the major driving forces of human activity (Danilova E.A. \& Yadov V.M., 2004, Huhlaev O.E. \&Kuznetsov I.M., 2008, Abrams D. \& Grant P.R., 2011). Human needs are the basis of human activity (need is a need, a person must satisfy his need, he begins to act). Needs are determined by living conditions (Titov R.S., 2013, Dollinger S.J. ,2002, Love P.G. , 2002, Peek L. , 2005, Stryker S. \& Burke P.J., 2000). Maslow A. Developed Hierarchical Theory of Satisfying Needs (Maslow A. H., 1954). Currently needs are considered the main motivating power of human activity (Belik A.A., 2011, Lazutkina M.A., 2012, Burke P., 2004, Park C.L., 2007, Purinton E.F., 2009). In order to organize effectively the activity of people, to increase their activity it is necessary to know their needs motivating them for these or that activities. So, it is necessary to study and analyze people's needs.

The aim of the study was to examine personal needs of healthy people and sick people with adequate social status, as well as people with the same health status and low social status.

\section{Subject and Methods of Research}

There were surveyed 49 men of middle age $38,7 \pm 3,2$ years old, employed, not suffering from neuro-psychiatric and physical illnesses and 43 women of middle age 39,8 $\pm 3,2$ years old, also not suffering from neuro-psychiatric and physical illnesses. There were also examined 82 person - 40 men (average age 43, $8 \pm 3,9$ years) and 42 women (average age 43, $0 \pm 3,9$ years) with chronic obstructive pulmonary disease (COPD) selected by the method of continuous sampling. To confirm the diagnosis of COPD there were used standard methods of clinical, radiological, laboratory, functional studies. All 82 COPD diagnoses were confirmed. All these persons had work, family, lived in a separate apartment, and had a monthly income above the subsistence level. All were the residents of Samara. Thus, the social status was analogical. These surveyed persons differed from healthy ones by having COPD.

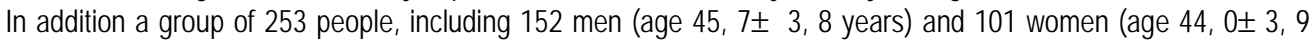
years) with fibro-cavernous pulmonary tuberculosis was examined. The average duration of tuberculosis was $7,5 \pm 1,8$ years. All patients with pulmonary tuberculosis were disabled by the disease. They were the citizens of Samara. Patients with chronic pulmonary tuberculosis were also taken by continuous sampling. Survey methods were common to confirm the diagnosis of pulmonary tuberculosis (clinical, laboratory, radiographic and functional methods). The diagnosis was 
confirmed for all the people.

Comparison of the clinical, functional, laboratory, X-ray data showed that the patients with COPD and the patients with chronic pulmonary tuberculosis had pulmonary fibrosis and emphysema on chest radiographs, disorders of ventilation conformed to the second degree of the mixed type, inflammation and intoxication syndromes were expressed moderately. So, manifestations of the disease were similar but COPD is a nonspecific pulmonary disease, and chronic pulmonary tuberculosis is a specific disease. Persons in these groups had different social status - patients with fibrocavernous pulmonary tuberculosis had low social status.

To study the personal needs of these people the author developed a special questionnaire. The basis of the questionnaire "personal needs" (rationalization suggestion number 218 of Samara State Medical University) is the theory of Maslow $[315,353]$. The questionnaire includes 6 main sections:

A -physiological needs;

$B$ - the need in security;

$\mathrm{C}$ - the need in recognition, acceptance by the members of the reference group;

$\mathrm{D}$ - the need in respect, approval, recognition of competence;

$\mathrm{E}$ - aesthetic and cognitive needs;

$F$ - the need in self-realization.

Section A (physiological needs) included: hunger, sleep and sexual needs.

Section B (the need in security) included: the need in security, the ability to provide living, the ability to defend social interests.

Section $C$ (the need in not breaking away from the group, the need in affection) included: the need to communicate with the colleagues, the preservation of family relations, the preservation of relationships with the children, maintaining good relations with others, the need to be loved, to belong to a respected group.

Section D (the need for respect, approval, recognition) included: the need in respect from others, the approval of actions and interests, in professional recognition, respect, in the course of professional and social growth,

Section $\mathrm{E}$ (aesthetic and cognitive needs) included: the need in religion, meditation on the sense of life, the need in art, the need in having hobbies.

Section $\mathrm{F}$ (the need in self-realization) included: assessing progress in life, the need in self-respect, the need in creativity, in the sense of self-satisfaction.

Thus the person had to answer 29 questions, to assess his or her own needs according to the scale.

The statistical analysis of the results was carried out by standard methods.

\section{Results}

The social characteristics of patients with chronic pulmonary tuberculosis are reported in Table 1.

Table 1. The social characteristics of the patients with fibro-cavernous pulmonary tuberculosis.

\begin{tabular}{|l|c|c|}
\hline Indicator & Percentage of men & Percentage of women \\
\hline Vocational secondary education & 56,8 & 60,7 \\
\hline Secondary education & 35,5 & 31,2 \\
\hline Higher education & 4,5 & 5,3 \\
\hline Basic education & 3,2 & 2,8 \\
\hline Smoking for more than 10 years & 97,8 & 46,7 \\
\hline Alcohol abuse & 52,3 & 12,5 \\
\hline Lives alone & 27,4 & 19,2 \\
\hline Lives with relatives & 33,9 & 26,8 \\
\hline Has full family & 30,6 & 41,2 \\
\hline Has incomplete family & 8,1 & 12,8 \\
\hline Widower (widow) & 11,6 & 9,4 \\
\hline Does not have a permanent place of residence & 5,7 & 2,1 \\
\hline Has a room in a communal apartment & 17,7 & 34,2 \\
\hline Has a private house without conveniences & 28,2 & 16,3 \\
\hline Has a separate apartment with conveniences & 48,4 & 47,4 \\
\hline Has no means for living & 54,8 & 43,2 \\
\hline
\end{tabular}




\begin{tabular}{|l|c|c|}
\hline The income is below the level of living & 40,3 & 52,7 \\
\hline The income is enough for the level of living or higher & 4,9 & 4,1 \\
\hline Unqualified work before the illness & 9,7 & 6,4 \\
\hline Qualified hard work before the illness & 56,5 & 32,1 \\
\hline Work associated with increased mental stress before the illness & 22,6 & 44,7 \\
\hline Qualified easy work before the illness & 11,2 & 16,8 \\
\hline The disease started and proceeded in corrective labor institutions & 64,3 & 40,6 \\
\hline The reason for the divorce was the disease of tuberculosis & 40,1 & 30,7 \\
\hline
\end{tabular}

As it can be seen from the Table 1, the majority of patients with chronic pulmonary tuberculosis had secondary or vocational education, alcohol abuse, smoking for more than 10 years, had no means for living or income was below the level of living. More than half of men and nearly half of the women took ill with tuberculosis in prisons. For some patients with pulmonary tuberculosis the disease led to divorce.

The personal needs of women according to the survey are presented in Table 2.

Table 2. Personal needs of women.

\begin{tabular}{|l|c|c|c|}
\hline & \multicolumn{2}{|c|}{$\mathrm{M} \pm \mathrm{m}$} \\
\hline The name of the scale & Healthy women & Women with COPD & $\begin{array}{c}\text { Women with chronic pulmonary } \\
\text { tuberculosis }\end{array}$ \\
\hline Physiological needs (PhN) & $4,2 \pm 0,3$ & $3,6 \pm 0,1^{*}$ & $3,1 \pm 0,5^{\star}$ \\
\hline The need in safety (SN) & $3,6 \pm 0,1$ & $3,1 \pm 0,1^{\star}$ & $3,2 \pm 0,1^{\star}$ \\
\hline The need in acceptance by the members of the group (AN) & $3,9 \pm 0,1$ & $3,6 \pm 0,1^{\star}$ & $3,9 \pm 0,3$ \\
\hline The need in respect (RN) & $3,7 \pm 0,2$ & $3,7 \pm 0,2$ & $3,5 \pm 0,2$ \\
\hline Aesthetic and cognitive needs (CAN) & $3,8 \pm 0,2$ & $3,4 \pm 0,1^{\star}$ & $3,8 \pm 0,3$ \\
\hline The need in self-realization (SRN) & $3,7 \pm 0,2$ & $3,2 \pm 0,1^{\star}$ & $3,0 \pm 0,5^{\star}$ \\
\hline
\end{tabular}

The note to Table 2. Indicators are given according to a five-point scale.

* means the statistically significant difference with the control.

According to the data of the table, physiological needs, safety needs, the need in acceptance by the members of the group as well as aesthetic and cognitive needs and the need for self-realization of women suffering from COPD are significantly lower than that of the healthy women. Statistically significant difference was not revealed only in the needs to have respect, professional recognition, respect from colleagues, neighbors, acquaintances, etc. The need to continue professional and social growth is equally important for healthy women and women with long quite heavy illness. Physiological needs, the need in security, the need in self-realization for the women with chronic pulmonary disease are significantly lower than that of the healthy women. The need to be accepted by the group, aesthetic and cognitive needs and the need to get respect of others are practically the same for the women with low social status about half of which are former prisoners and for the healthy women with adequate social status.

The personal needs of men according to the survey are presented in Table 3.

Table 3. Personal needs of men

\begin{tabular}{|l|c|c|c|}
\hline & \multicolumn{2}{|c|}{ M $\pm \mathrm{m}$} \\
\hline The name of the scale & Healthy men & Men with COPD & Men with chronic pulmonary tuberculosis \\
\hline Physiological needs (PhN) & $3,7 \pm 0,1$ & $3,5 \pm 0,2$ & $2,9 \pm 0,2^{\star}$ \\
\hline The need in safety (SN) & $3,7 \pm 0,1$ & $3,0 \pm 0,2^{\star}$ & $3,3 \pm 0,2^{\star}$ \\
\hline The need in acceptance by the members of the group (AN) & $3,8 \pm 0,1$ & $3,1 \pm 0,2^{\star}$ & $3,2 \pm 0,1^{\star}$ \\
\hline The need in respect (RN) & $3,6 \pm 0,2$ & $3,2 \pm 0,2$ & $3,3 \pm 0,2$ \\
\hline Aesthetic and cognitive needs (CAN) & $3,6 \pm 0,1$ & $2,8 \pm 0,2^{\star}$ & $2,0 \pm 0,2^{\star}$ \\
\hline The need in self-realization (SRN) & $3,6 \pm 0,1$ & $2,5 \pm 0,2^{\star}$ & $2,5 \pm 0,4^{\star}$ \\
\hline
\end{tabular}

The note to Table 3. Indicators are given according to a five-point scale.

* means the statistically significant difference with the control.

The results of the table indicate that men suffering from COPD in contrast to the healthy men have significantly lower security needs, aesthetic and cognitive needs and the need for self-realization. Physiological needs and the need to get respect are similar for the men suffering from COPD and healthy men. Eating, sleeping, sex, respect from others are 
important for all the men with adequate social status regardless of health status.

For the men with chronic fibro-cavernous pulmonary tuberculosis the need to be accepted by the group, aesthetic and cognitive needs and the need in self-realization are significantly lower than for the healthy men. Only the need in respect for the ill men with low social status is the same as for the healthy men.

Then the correlation analysis between the objective clinical, laboratory, radiological, functional indicators and personal needs was made. No significant dependence was found between clinical, laboratory, radiological indicators and personal needs. A significant dependence was found between respiratory function and personal needs.

The results of the correlation analysis between respiratory function (RF) and personal needs (PN) for the women with COPD are presented in the Table 4.

Table 4. Coefficients of correlation between RF and PL for the women with COPD

\begin{tabular}{|c|c|c|c|c|c|c|}
\hline RF & PhN & SN & AN & RN & CAN & SRN \\
\hline FEV-1 & $0,59^{*}$ & $0,55^{*}$ & $0,24^{*}$ & $0,45^{*}$ & $0,51^{*}$ & $0,51^{*}$ \\
\hline FVPL & $0,46^{*}$ & $0,44^{*}$ & 0,22 & $0,41^{*}$ & $0,49^{*}$ & $0,47^{*}$ \\
\hline PVR & $0,48^{*}$ & $0,36^{*}$ & 0,23 & $0,39^{*}$ & $0,47^{*}$ & $0,49^{*}$ \\
\hline
\end{tabular}
*- correlation indicators are given when $\mathrm{p}=0,05$
** RF - respiratory function; FEV - forced expiratory volume; FVPL - forced vital power of lungs; PVR - peak volume rate

The data of the table show the presence of the positive correlation of all indicators of respiratory function with personal needs. The highest correlation coefficient was observed between FEV-1 and PhN ( $r=0,59 ; p=0,05)$.

The results of the correlation analysis between respiratory function (RF) and personal needs (PN) for the men with COPD are presented in the Table 5.

Table 5. Coefficients of correlation between RF and PL for the men with COPD

\begin{tabular}{|c|c|c|c|c|c|c|}
\hline RF & PhN & SN & AN & RN & CAN & SRN \\
\hline FEV-1 & $0,67^{*}$ & 0,20 & $0,57^{*}$ & 0,12 & $0,51^{*}$ & $0,67^{*}$ \\
\hline FVPL & $0,36^{*}$ & 0,19 & $0,44^{*}$ & 0,16 & $0,47^{*}$ & $0,54^{*}$ \\
\hline PVR & $0,48^{*}$ & 0,21 & $0,47^{*}$ & 0,19 & $0,42^{*}$ & $0,49^{*}$ \\
\hline
\end{tabular}

The data of the table show the presence of the positive correlation between the indicators of RF with four out of six indicators of PN. The largest correlation coefficient was observed between FEV-1 and PhN ( $r=0,67 ; p=0,05)$.

The results of the correlation analysis between respiratory function (RF) and personal needs (PN) for the women with fibro-cavernous tuberculosis are presented in the Table 6.

Table 6. Coefficients of correlation between RF and PL for the women with fibro-cavernous tuberculosis

\begin{tabular}{|c|c|c|c|c|c|c|}
\hline RF & PhN & SN & AN & RN & CAN & SRN \\
\hline FEV-1 & $0,29^{\star}$ & $0,32^{\star}$ & 0,22 & 0,18 & 0,26 & $0,34^{\star}$ \\
\hline FVPL & 0,21 & 0,23 & $0,33^{*}$ & 0,21 & $0,34^{\star}$ & $0,36^{\star}$ \\
\hline PVR & $0,27^{\star}$ & 0,24 & 0,19 & 0,16 & 0,27 & $0,32^{\star}$ \\
\hline
\end{tabular}

The women with chronic pulmonary tuberculosis had positive correlation of personal needs with pulmonary ventilation. The highest correlation coefficient is marked between the need for self-realization and FVPL $(r=0,36 ; p=0,05)$. There is also a significant dependence between satisfaction of cognitive and aesthetical needs and FVPL $(r=0,34 ; p=0,05)$.

The results of the correlation analysis between respiratory function (RF) and personal needs (PN) for the men with fibro-cavernous tuberculosis are presented in the Table 7.

Table 7. Coefficients of correlation between RF and PL for the men with fibro-cavernous tuberculosis

\begin{tabular}{|c|c|c|c|c|c|c|}
\hline RF & PhN & SN & AN & RN & CAN & SRN \\
\hline FEV-1 & $-0,18$ & $-0,32$ & $-0,08$ & $-0,05$ & $-0,04$ & 0,02 \\
\hline FVPL & $-0,10$ & $-0,15$ & $-0,16$ & 0,01 & $-0,02$ & $-0,06$ \\
\hline PVR & $-0,35^{\star}$ & $-0,15$ & $-0,19$ & 0,11 & 0,08 & $-0,06$ \\
\hline \multicolumn{7}{|c}{363} \\
0
\end{tabular}


The men with chronic pulmonary tuberculosis had negative correlation between PVR and the degree of satisfaction of physiological needs $(r=-0,35 ; p=0,05)$. That is, the higher the ventilation rate, the higher are physical abilities and sexual needs as well as hunger.

\section{Discussions}

Practically healthy men and women, as well as the men and women suffering from COPD, were working people. Their social status was adequate.

Women with COPD had significantly lower physiological needs. This is understandable. Functional indicators showed a second degree of impairment of lung ventilation of the mixed type. These women are forced to save movements, any sudden movement is accompanied by shortness of breath, night sleep is disturbed because of shortness of breath, food intake is also accompanied by shortness of breath, as well as the satisfaction of sexual needs. Requirements for safety for the women with COPD are significantly lower. The survey questions were designed to identify the need for security, the ability to provide living, to defend social interests. As the results of the study show the women suffering COPD are less concerned about the ability to provide their future and to defend social interests. They are less concerned about the future than about the present.

The need to communicate with the colleagues, the preservation of family relations, the preservation of family and relationships with the children, maintaining good relations with others, the need to be loved, to belong to a respected group for the women suffering from COPD was significantly lower than that of the healthy women with the same social status. The aesthetic and cognitive needs of these patients were also significantly lower than that of the healthy persons. They had little interest in thinking about the meaning of life or art. Health problems forced out different hobbies and left no room for religion. The need in self-realization for the women with COPD was significantly lower than that of the healthy women. They are not satisfied with themselves and the achievements in life, have no desire to do more, they did not show a creative approach to solving problems and do not feel the need in personal and creative growth, selfimprovement, self-development and self-actualization.

With all the differences in the needs of the women with COPD and the healthy women they all have the need which is equally important - the need in respect. All these women had an adequate social status.

The social status of the women suffering from fibro-cavernous tuberculosis was lower than that of the practically healthy women and the women with COPD. About half of the women earlier were in prisons, about half used to smoke for more than 10 years, $12,5 \%$ abused alcohol, 34,2\%lived in communal flats, $43,2 \%$ did not have any means for living, $52,7 \%$ had the profit lower subsistence level. For $40,6 \%$ the illness started in corrective labour institutions. For 30, $7 \%$ of the women the illness was the reason of the divorce. The results showed that their need in acceptance by the group, the need in respect, aesthetic and cognitive needs did not differ from the needs of practically healthy women with an adequate social status. For the women with low social status it is important to belong to the group, to have respect from relatives and other people, to have personal and professional approval, to be religious, to have hobbies and interests.

Significant correlation was revealed between the indicators of RF and all personal needs of the women with COPD. That means that for the women with an adequate social status all personal needs depend on the state of health.

For the women with COPD all personal needs except the need in respect depend on RF. For them it is difficult to move because of shortness of breath, their night sleep is worse because of coughing and shortness of breath. These women were disabled for COPD. But for them respect was more important than the state of health. Their social status was low. Evidently the need in respect from the others is compensatory. And it dominates health problems.

Physiological needs of the healthy men and the men with COPD are the same. Eating, sleeping and having sex is important for all the men regardless the state of health. Physiological needs of the men with fibro-cavernous tuberculosis are significantly lower. Probably it is explained by the fact that $43,2 \%$ had no means for living and $52,7 \%$ had the profit lower than subsistence level. The need in safety and the need to be accepted by the group, aesthetic and cognitive needs are lower for the ill men. The need in self-realization is lower, too. In comparison with the healthy men they are less interested in future, social problems and having their own point of view, in creative and personal development.

But the need to be respected is equally intrinsic for all the men - the healthy men, the ill men with an adequate social status and the ill men with a low social status.

Correlation analysis between the clinical, laboratory, radiological, functional indicators and personal needs was made. Significant correlation between the indicators of functional capacity of the lungs and personal needs was also revealed.

In men with COPD with an adequate social status had the dependence of all indicators of the personal needs with the individual lung function parameters except the need for safety and respect from others. 
Coughing, shortness of breath, weakness, poor night sleep because of the illness, physical disabilities directly affect the personal needs making them lower in comparison with the healthy men. But respect from others, the ability to provide the future, to defend social interests for the men with COPD are more important than their own health.

For the men with fibro-cavernous tuberculosis the dependence of the personal needs with the individual lung function parameters was also revealed but the reverse dependence. The more is the shortness of breath the lower is the personal need. It can be explained by the social status of the men with fibro-cavernous tuberculosis. $52,3 \%$ had alcohol abuse, 54,8\%did not have means for living, 64,3\%the illness started in prisons and in corrective labour institutions. Such persons need to be in a good physical state to protect themselves. For them to be accepted by the reference group means to be able to participate in group conflicts with physical violence. The questioned persons with chronic pulmonary tuberculosis had violations of lung ventilation of the second degree of the mixed type. The men cannot make any sudden movements, they save movements, they have constant coughing and shortness of breath. Therefore, they do not seek to an appropriate social status of their reference group. However, there is also a positive correlation, although unreliable, between the speed performance of lungs and the need for respect. For the men with low social status the need to get respect from others is also independent of their health status. The obtained data should be used by personnel managers, social psychologists, family psychologists. The need in respect in the pyramid of Maslow is below physiological needs, the need in safety and the need to be accepted by the group. The personal needs of the ill men and women are lower in comparison with the healthy men and women. They are less interested in relationship with their relatives and friends, their future, creative development and self-realization. It is explained by the state of their health - constant coughing and shortness of breath. But the need to be respected is not connected with respiratory function. It is the only need not connected with the state of health. It is equally true for the men with COPD, for the women with COPD and fibrocavernous lung tuberculosis. The men with COPD with low social status do not have great intention to enter reference group where it is necessary to protect yourself physically or creatively develop yourself. It is explained by their poor physical state. But respect from others is important for them too. The need in respect from others is equally important for the men and the women independently of their state of health and real social status.

This need to be respected should be more widely used as a motivation for treatment, work, education and career development.

\section{Conclusion}

1. Personal needs of the women suffering from COPD with an adequate social status are lower than that of the healthy women except the need in respect.

2. For all the women with an adequate social status all personal needs including the need in respect depend on the state of health.

3. All the women with a low social status had the same need to be accepted by the group, to get respect from the others as well as cognitive and aesthetic needs as the healthy women.

4. For the women with a low social status all personal needs depend on the state of health except the need in respect. The respect of the others is more important for them than the state of health.

5. The ill men with an adequate social status have the same physiological needs and the need in respect as the healthy men.

6. The men with COPD with a low social status have lower personal needs except the need in respect.

7. For the men with an adequate social status the ability to provide the future and respect from others are more important than the state of their health.

8. For the ill men with a low social the worse is the health the lower are the personal needs except the need in respect. The respect of the others is more important for them than the state of health.

9. The need to be respected should be more widely used as a motivation for treatment, work, education and career development.

\section{References}

Belik A.A. The "I" Theory of J.G. Meed and Psychological Anthropology //Social Psychology and the Society. 2011. № 1.

Vahitova Z.Z. Social and Psychological Peculiarities of Economic Relations (on the example of employees and employers): Thesis abstract of the Candidate of Psychological Sciences. M., 2004.

Danilova E.A., Yadov V.M. Contextually-Labile Social Identity - the Norm of the Modern Dynamic Societies //Sociological Research. 2004.№10.4. 
Ivanova N.L. The Problem of Social Identity in Psychological Research //The World of Psychology. 2012. № 1.

Lazutkina M.A. Theoretical Analysis of the Structure of Religious Identity and the Methods of its Measurement // Almanac of the Modern Science and Education.Tambov. 2012. № 12 (67). P. I.

Patosha O.I. Motivation of the Behaviour of Customers on the Market of Domestic Products: Thesis abstract of the Candidate of Psychological Sciences. M., 2008.

Stepanova E.N., Eflova M.A. Social Exclusion of Imprisoned and Ex-imprisoned People in Russia //Power. 2012. № 1.

Suhova E.V., Lebedeva N.O. The Hierarchy of Personal Values as a Mechanism of Motivation for Treatment. The News of Samara Scientific Center of the Russian Academy of Sciences, a special edition "Actual Problems of the Humanities" - 2005.- № 2.- $p$. 76-80

Titov R.S. The Concept of Individual Religiosity of G.. Allport: The Concept of Religious Orientations//Cultural and Historical Psychology. 2013. № 1.

Huhlaev O.E., Kuznetsov I.M. Nationalism as a Social and Psychological Phenomenon: To the question//Acmeology. 2008. № 3; 4.

Abrams D., Grant P.R. Testing the Social Identity Relative Deprivation (SIRD) Model of Social Change: The Political Rise of Scottish Nationalism // British Journal of Social Psychology. 2011. Vol. 51.

Breakwell G.M. Resisting Representations and Identity Process // Paper on Social Representations. 2010. Vol. 19.

Burke P. Identity and Social Structure: The 2003 Cooley Mead Award Address //Social Psychology Quarterly. 2004. Vol. 67.

Dollinger S.J. Religious Identity: An Autophotographic Study // International Journal for the Psychology of Religion. 2001. Vol. 1. Is. 2.

Love P.G. Comparing Spiritual Development and Cognitive Development // Journal of College Student. 2002. Vol. 43. № 3.

Maslow A. H. Motivation and Personality. — New York: Harpaer \& Row, 1954.

Park C.L. Religiousness/Spirituality and Health: A Meaning Systems Perspective // Journal of Behavioral Medicine. 2007. Vol. 30.

Peek L. Becoming Muslim: The Development of a Religious Identity // Sociology of Religion. 2005. Vol. 66.

Purinton E.F. Compensatory or Conspicuous Consumption? // Bling It On, American Society of Business and Behavioral Sciences. 16 th Annual Conference. 2009. Vol. 16.

Stryker S., Burke P.J. The Past, Present and Future of Identity Theory // Social Psychology Quarterly. 2000. Vol. 63. 